CIDADANIA SEXUAL SOB SUSPEITA: UMA MEDITAČ̃̃O SOBRE AS FUNDAÇÕES HOMONORMATIVAS E NEO-LIBERÁIS DE ŨA CIDADANIA DE "CONSOLAÇÃO"

SEXUAL CITIZENSHIP UNDER SUSPICION: A MEDITATION ON THE HOMONORMATIVE AND NEOLIBERAL FOUNDATIONS OF A "CONSOLATION" CITIZENSHIP

João Manuel de Oliveira

Universidade do Porto, Porto, Portugal

\title{
RESUMO
}

Este artigo revisita criticamente as noções de cidadania sexual, procedendo a uma reflexão sobre as suas fundações homonormativas - decorrentes da heteronormatividade - e neo-liberais - decorrentes do atual estado da formação social capitalista. Recorremos à análise de estatísticas sobre o casamento entre pessoas do mesmo sexo em Portugal e à análise de discurso de uma entrevista, usada como estudo de caso, para evidenciar o modo como uma economia política heterossexual sob a capa da homonormatividade emerge para estruturar a cidadania sexual e como esta é igualmente, por via da sua associação ao consumo se transforma apenas numa cidadania de consolação, geradora de hierarquias dentro da população LGBT entre quem tem recursos para aceder aos bens de consumo e quem não pode efetuar esse acesso. Discutimos na conclusão, o modo como esta cidadania sexual emerge como pharmakon, mantendo-se conceptualmente ambivalente.

Palavras-chave: homonormatividade; heteronormatividade; cidadania sexual; neo-liberalismo; queer.

\begin{abstract}
This article critically revisits the notions of sexual citizenship, while analysing its homonormative and neoliberal foundations - effect of heteronormativity and of capitalist social formation. Using an analysis of the statistics of same sex marriage in Portugal and a discourse analysis to one interview, used as a case study, evidence is provided to illustrate how a heterosexual political economy using homonormativity emerges to structure sexual citizenship. Also sexual citizenship transformed in a mode of consumption turns out to be a consolation citizenship that generates hierarchies within the LGBTIQ population between the ones that can afford that access to commodities and the ones that are not able to do so. In the conclusion, we show that sexual citizenship is an ambivalent concept, discussing it as a pharmakon.
\end{abstract}

Keywords: homonormativity;heteronormativity; sexual citizenship; neoliberalism; queer.

\section{Coordenadas conceptuais}

Neste texto pretendo apresentar uma análise sobre as relações intrincadas entre cidadania sexual e normas de género, assentes na heterossexualidade hegemónica (Butler, 2004) e neo-liberalismo. Estas coordenadas, género e sexualidade, são essenciais para compreender o espaço conceptual, a partir do qual se está a produzir esta reflexão. Epistemologicamente, refiro-me ao feminismo queer, um espaço de preocupação teórico-política de nomeação recente que tem vindo a discutir uma série de fenómenos e processos psicossociológicos a partir de um entendimento que analisa não exclusivamente nem o género nem a sexualidade, mas que antes procede a um enquadramento que incorpora ambos na sua análise (Jagose, 2009; Marinucci, 2010).
Normas de género, heteronormatividade e homonormatividade

Os estudos de género bem como os estudos LGBT (lésbicos, gay, bissexuais e trans) têm vindo a produzir um questionamento extremamente fértil dos efeitos das normas sobre a construção das subjetividades. Esses trabalhos decorrem de uma analítica foucaultiana (Foucault, 1976) a partir da qual analisam a produção dos sujeitos e simultaneamente a sua sujeição às normas. Este pendor analítico permite introduzir uma especial atenção aos modos como os sujeitos sexuais são constituídos e quais os constrangimentos que a sujeição a essas normas impõe. Categorias que, outrora, foram utilizadas em contextos médicos ou científicos, passaram forma a denominar 
grupos humanos como por exemplo "heterossexuais", "homossexuais", "lésbicas" e "transexuais". Este processo histórico de constituição de sujeitos sexuais, descrito por Foucault (1976), é fundamental para um entendimento dos modos como estas categorias são usadas, ressignificadas e empregues para nomear grupos ou comunidades. Como mostra o trabalho de Halberstam (2005), essas categorias apresentamse como lugares necessariamente problemáticos, recorrendo à noção de problemas de género introduzida por Butler (1990). A analítica que Butler introduz a partir de uma problematização quer do pensamento foucaultiano, quer do pensamento feminista de Monique Wittig (2005), implica repensar estes grupos para lá do pendor essencialista destas categorias, vendoas como o efeito de performances que se repetem ao longo do tempo produzindo assim uma metafísica de substância tida como verdadeira a partir de um dado quadro regulatório (performatividade). Desta forma explicita o modo como as normas permitem constituir sujeitos dentro de uma heterossexualidade hegemónica e consequentemente sobrenormativa. O conceito de heteronormatividade surge na literatura dos estudos LGBT através do artigo de Morin (1977) e começa por ser descrito como um enviesamento heterossexual, um sistema normativo de crenças que considera a heterossexualidade como mais "natural" e superior à homossexualidade.

Neste trabalhoanalisareia incorporação das normas de género no quadro da heterossexualidade hegemónica recorrendo ao conceito de homonormatividade, uma modalidade particular da heteronormatividade, através da qual se mostra como a população gay e lésbica se torna aceitável aos olhos da heterossexualidade hegemónica através de uma progressiva conformidade à heteronormatividade (Duggan, 2003).

Este aspeto da heteronormatividade torna-a também menos vísivel e evidente, nomeadamente porque com esta normalização, por parte da comunidade gay e lésbica, a heteronormatividade parece elidir-se dado que até a população mais afetada por estas normas se sujeita à mesmas. Necessariamente, é preciso relembrar que tal produção da homonormatividade se efetua no quadro de um modelo neo-liberal (Richardson, 2005) para além de surgir ligada a determinadas reivindicações do próprio movimento LGBTIQ (lésbico, gay, bissexual, trans, intersexo, queer) que podem ser vistas como neo-liberais, pela importância que atribuem à família e à constituição de relações de longa duração, monogâmicas e modeladas pelo casamento (Richardson, 2004).

Assim o conceito de homonormatividade tornase particularmente relevante para entender o modo como a população LGBTIQ faz perdurar o legado da heteronormatividade no plano de uma cidadania voltada para o consumo num quadro neoliberal, na despolitização das reivindicações e no reforço do binarismo de género dentro da própria comunidade, constituindo assim uma hierarquização dentro dessa comunidade em termos de grau de aceitabilidade e de conformidade dos corpos às normas de género. Constitui-se assim uma economia heterossexual que constantemente regula, fortifica e controla as suas fronteiras (Butler, 1993).

\section{Neo-liberalismo e cidadania sexual}

É necessário contextualizar o que entendemos por sistema neo-liberal, no qual estas relações sociais decorrem. Como Diane Richardson (2005), entendemos que o neo-liberalismo apresenta uma faceta económica e uma faceta cultural. Stuart Hall (2011) considera que o neo-liberalismo apresenta uma dicotomia fundadora entre Estado (visto como "tirânico e opressivo") e os indivíduos "livres e possuidores (de bens)" (p. 10). Esta dicotomia implica então que o Estado não deverá regular os mercados, determinar de que modo esses indivíduos podem dispôr dos seus bens e dos seus lucros, em suma interferir com a sua liberdade (económica). Este tipo de pensamento de economia política teve o seu início na crítica às políticas do Estado Social, que de acordo com os seus detratores, implicou a desresponsabilização individual na produção de riqueza. A célebre frase de Margaret Thatcher subsume este tipo de pensamento "A sociedade não existe. Só há individuos e as suas famílias" (citada por Hall, 2011, p. 11). Este foco no indivíduo e o esquecimento a que são votados os coletivos, é pois uma marca forte deste tipo de pensamento, assente na ideia do mercado como grande força motriz em detrimento do Estado, que deve encolher e tornar-se mínimo em termos de intervenção social e económica.

O neo-liberalismo enquanto aplicação destas ideias é uma realidade multiforme, com inúmeras configurações. Os ataques ao Estado Social na Europa, a aplicação de algumas políticas monetaristas nalguns países da América Latina ou o capitalismo de estado na China são algumas das possíveis versões do neoliberalismo. Focamo-nos nos ataques ao Estado Social, através de Stuart Hall, como forma de tornar evidente os novos arranjos sociais propostos pelo neo-liberalismo. Em primeiro lugar, e reportandose ao governo do Reino Unido, Hall identifica como alvo dos ataques neo-liberais alguns indivíduos entendidos como tendo uma relação de dependência face ao Estado e dos serviços públicos. Aposentados/ as, desempregados/as, mães solteiras, pobres, são 
alguns dos grupos que veem esses serviços e sobretudo as suas prestações sociais diminuir. Hall enuncia também a privatização dos bens públicos como outra decorrência da revolução neo-liberal. Em muitos países europeus, áreas centrais dos serviços público foram inteiramente privatizadas sob a capa da necessidade de cortar custos ao Estado e emagrecer o espectro da sua intervenção. Por outro lado, esta tentativa de cortes em múltiplas áreas e serviços implica, de igual forma, uma desinvestimento do Estado na qualidade de vida dos cidadãos e das cidadãs. Conforme mostra Sousa Santos (2005), três estratégias emergem no quadro do neo-liberalismo: privatização, mercantilização e liberalização, verdadeiros mantras desta revolução neo-liberal em curso.

Esta doutrina do mercado como deus ex machina e do Estado como um incómodo que importa emagrecer implica a tentativa de uma hegemonia, que apesar de estar em processo de construção, já pode implicar para Hall (2011) a classificação de um projeto hegemónico.

Para Boaventura de Sousa Santos (2005), a matriz da governação neo-liberal nas sociedades ocidentais implica uma redefinição dos objetivos da chamada crise de legitimidade ocorrida nos anos 70 , com a crítica ao contrato social que os movimentos sociais vieram propôr. Assim e em vez de incluir mais pessoas neste contrato, o que o pensamento neoliberal fez foi transformar esta reivindicação numa mitigação da expectativas que as sociedades deveriam ter face ao Estado, que passa a retrair o seu espectro de intervenção, domesticando-se, neste processo, as possibilidades de participação social. Não é qualquer pessoa que pode participar, são apenas alguns atores ou interesses (stakeholders). Estado e excluíd@s acabam por ser a parte esquecida por esta forma de governação, o que é relevante para grupos como o grupo em apreço neste artigo.

Falta, para terminar esta seção centrada nas coordenadas conceptuais que deram origem a este trabalho, mencionar as teorias da cidadania, nomeadamente as que se focaram na cidadania sexual. Num trabalho anterior que realizámos (Nogueira \& Oliveira, 2010) fizemos essa genealogia. Vou apenas traçá-la em esboço largo neste contexto. O modelo de cidadania de Marshall (1950) com três formas de cidadania: civil, política e social foi bastante criticado pelos setores feministas e LGBTIQ por assentar quase exclusivamente na legitimação que o Estado tinha que dar a estas formas, reduzindo a participação cidadã àquela que o Estado sanciona ou permite (Carneiro, 2009; Nogueira $\&$ Silva, 2003). Igualmente a falta de reconhecimento da cidadania enquanto construto repetidamente sexualizado, genderizado ou racializado (Richardson, 2004).
Estas lacunas nas propostas vão dar origem a propostas que visam não só reorientar o sentido possível da cidadania para dar conta das possibilidades de participação cidadã, mas também sexualizar o conceito de cidadania. O conceito de cidadania sexual (Evans, 1993) foi avançado como uma forma de discutir aspetos de uma cidadania diferenciada, marcada neste caso, pela questão da sexualidade e por uma reivindicação de direitos e responsabilidades que tem vindo a ser negada em função da heterossexualização da figura do bom cidadão (Richardson, 2005). Como mostra Davina Cooper (2006) há três aspetos interrelacionados no âmbito da cidadania sexual e que refletem alterações nas sociedades contemporâneas em relação aos indivíduos LGBTIQ: a atribuição legal de direitos e responsabilidades, aquisição de estatuto e reconhecimento social e a incorporação dentro da sociedade como membros de pleno direito. Necessariamente e como reflete Richardson (2005), este processo envolveu ativamente políticas de semelhança (com heterossexuais) e normalização. É precisamente nesse âmbito que situamos a nossa análise, seguindo as propostas de Cooper (2006) e Richardson (2005), olhando para o modo como a cidadania sexual é simultaneamente útil e necessária para que as sociedades reconheçam direitos e responsabilidades a estes grupos diferenciados, mas como ao mesmo tempo, a cidadania sexual encerra no quadro atual neo-liberal, um processo de normalização e de assimilação. A pesquisa de Ana Cristina Santos (2009) sobre o movimento LGBT em Portugal é um bom exemplo do modo como, no âmbito da apresentação pública das reivindicações do movimento em Portugal, as performatividades públicas implicam uma heteronormatividade interna, ocultando performances mais transgressoras e visibilizando outras mais normalizadas e logo mais assimiladas.

Estas coordenadas - cidadania sexual, normas de género, heteronormatividade e homonormatividade num quadro de um regime económico-social neoliberal serão utilizadas neste trabalho para analisar dois casos, aparentemente não relacionados, mas que no meu entender configuram determinadas normas dentro de um quadro de uma economia política heteronormativa.

\section{Casamentos para uns, adoção só para outros}

Tal assunto parece particularmente relevante no Portugal contemporâneo, onde através da lei 9/2010 de 31 de maio, o casamento deixou de ser exclusivo para pessoas de sexo diferente (entre si), mas onde também se adicionou um artigo à lei (artigo $3^{\circ}$ ) proibindo os 
casais de pessoas do mesmo sexo de adotar. Ou seja, no mesmo dia em que se conseguiu fazer promulgar uma lei que salvaguarda a possibilidade de casamento entre pessoas do mesmo sexo, uma discriminação fica inscrita na lei. Tal procedimento parece-me ilustrativo da profunda contradição que a heteronormatividade instala: se por um lado, atribui aos casais de pessoas do mesmo sexo a possibilidade de contrair casamento, por outro retira-lhes a possibilidade de adotar crianças, estabelecendo assim um regime de casamento que não é inteiramente igual do ponto de vista legal. Contudo, e saindo de uma lógica estrita de direitos formais, é também importante perceber de que modo a legislação é aplicada e de que forma esta igualdade (não completamente igual) de jure se coaduna a uma igualdade de facto.

Se olharmos para os dados do Ministério da Justiça ${ }^{1}$ relativos a 2010, e incluindo casamentos nos consulados, realizaram-se 277 casamentos. A sua maioria na Grande Lisboa (50,54\%), Região Centro $(12,64 \%)$ e Grande Porto (11,50\%). A concentração dos casamentos em meio urbano evidencia uma assimetria que marca um aspeto importante desta questão: a maior dificuldade em aceder ao casamento em meio rural, mas muito provavelmente também, o menor de casais de pessoas do mesmo sexo no meio rural. Esta análise elucida o modo como as condições para a concretização das políticas de igualdade variam de acordo com outras lógicas sociais, obedecendo a padrões marcados pelas assimetrias do Portugal contemporâneo, nomeadamente em termos da concentração da população nos meios urbanos. Tais dados podem ser igualmente confrontados com os resultados do estudo que conduzimos (Costa, Oliveira \& Nogueira, 2010) em que foram reportados elevados índices de discriminação de pessoas LGBT em Portugal, nomeadamente fora dos grandes meios urbanos. Os resultados por sexo ilustram também uma realidade interessante: um terço de casamentos entre mulheres versus dois terços entre homens. Assim facilmente se depreende que as condições para a igualdade na prática diferem da igualdade na lei.

Contudo será que tudo o que diga respeito a gays e a lésbicas em particular ${ }^{2}$ se esgota numa lógica de direito à família? Se alargarmos de fato o âmbito dos representados (no sentido de constituencies) no movimento gay e lésbico para incluirmos grupos como bissexuais, queer, trans, intersexo, poliamor, entre outras posições, a lógica passa a ser completamente distinta. Pois para estes grupos, bem como para outros grupos progressistas como feministas, grupos antirracistas e outr@s, será necessário lidar com toda uma série de problemáticas que extravasam os direitos à família. Dois exemplos, que creio estarem interelacionados, mostram a diversidade de políticas feministas e antirracistas que é necessário articular. Se pensarmos nos usos dos direitos das mulheres por parte da Administração Bush como forma de legitimar a guerra contra o Afeganistão e contra os "terroristastalibans" que punham em causa esses direitos (Abu Lughod, 2002), com um célebre discurso de Laura Bush a legitimar a guerra como uma luta pelos direitos das mulheres. Ou recuando no tempo, na análise de Gayatri Spivak (1993) sobre usos imperialistas das leis britânicas contra o sati na Índia colonizada (imolação das viúvas na pira funerária do marido), em que a missão britânica legitimada como "humanista" e de libertação das mulheres de costumes "selvagens" era uma justificação para manutenção do colonialismo. Lapidar a frase de Spivak (1993, p. 94): "white men are saving brown women from brown men" (homens brancos que tentam salvar mulheres pardas de homens pardos, em Português, numa tradução inglória). Contudo esta frase é introduzida no texto como maneira hiperbólica de contrastar com a justificação contrária, usada pelos homens indianos, "as mulheres queriam mesmo morrer" (Spivak, 1993, p. 94). Em ambas as frases não é possível escutar a voz subalterna das mulheres, duplamente silenciada pela sua condição de mulheres e colonizadas. Assim Spivak analisa o modo como esta condição das mulheres é usada como significante da boa sociedade, orientada pelos valores do progresso, em suma do imperialismo ocidental. Esta frase é usada ao longo do texto, não como uma crítica em relação à existência da lei, mas como um modo de analisar que a simples mudança legal não produziu nenhuma mudança na formação dos sujeitos. Ou seja, se tomarmos esta conclusão de Spivak como aplicável a outros contextos, é possível entender que a produção da lei não é suficiente para produzir efeitos nalgumas posições de sujeito. A minha intenção, ao invocar contextos distais, mas simultaneamente proximais conceptualmente, é retraçar uma possibilidade de entendimento desta questão.

Seguindo este raciocínio, um outro elemento que pode ajudar a compreender esta questão, tem a ver com o movimento Occupy e com os inúmeros grupos que o constituiram. Muito recentemente, um grupo conhecido no Twitter como \#OccuPride e que usa a assinatura coletiva de Trans World Order veio publicar um manifesto que aborda a questão das reivindicações LGBTIQ (Trans World Order, 2012) e acusa os movimentos mainstream de se cingirem à defesa de direitos simbólicos que essencialmente são usados pelos membros privilegiados das comunidades LGBT. Assim afirmam a importância de questionar a importância atribuída a estes direitos como o casamento 
e questionam a estratégia de tentar tornar a comunidade LGBT assimilável a instituições que são assentes em "lucro, hierarquia, competição, encarceramento e coerção" (Trans World Order, 2012). Reclamam ainda a diversidade da comunidade e evidenciam que grande parte do grupo está sujeito a discriminações de toda a ordem e às violências que as acompanham. Assim consideram a estratégia do casamento como essencialmente simbólica e que serve apenas os interesses de gays brancos com capital económico. Esta crítica para lá da muito discutida questão do assimilacionismo traz as preocupações com a divisão em classes sociais dentro da comunidade LGBTIQ e defende a necessidade de que os movimentos passem a integrar mais preocupações com cuidados de saúde, políticas de imigração, respeito e autonomia de toda a diversidade dentro da população LGBTIQ. Ora, mais uma vez, e se optarmos pela leitura ligada às preocupações com a igualdade e a diversidade sexual, já não em comparação com a heterossexualidade, mas tomando em linha de conta a própria diversidade intragrupo, percebe-se que determinadas políticas não são verdadeiramente pensadas para tod@s as pessoas dentro da comunidade, mas dirigidas a determinados setores da mesma. O caso do casamento ilustra o modo como mesmo um esforço político pela igualdade pode ser significado como privilegiar os que já são privilegiados, em detrimento de outros grupos dentro da comunidade LGBTIQ, como denuncia o manifesto. Igualmente é preciso considerar que a opção dos movimentos pelo casamento também limita perspetivas de luta pela diversidade sexual e de género, no sentido em que reduz o horizonte de possibilidades à figura espectral da família. Como mostra Halberstam (2011), a opção do movimento em assentar as suas possibilidades de reivindicação no casamento pode ser entendida como uma estratégia conservadora, no sentido em que reduz o potencial de formas alternativas de reconhecimento da diversidade doméstica e introduz um estatuto de privilégio até económico a quem opta pelo casamento em detrimento de outras soluções relacionais.

Recorrendo a Vale de Almeida (2012), é possível detetar na sua narrativa da luta pelo direito ao casamento em Portugal, uma preocupação com a simbólica do casamento como uma das justificações da sua importância em termos das reivindicações dos movimentos LGBT. Vale de Almeida (2009) apresenta o casamento como uma instituição paradoxalmente vazia, analisando-o como

uma das formas contratuais que podem recobrir ou não determinados conteúdos relacionais. $\mathrm{O}$ casamento, no debate que tenho abordado funciona mais como um símbolo de inclusão, cidadania e reconhecimento e prossecução da modernidade ... ou da manutenção da ordem e do regime de género e sexual tradicional. (p. 115)

O uso do símbolo como marca da cidadania de inclusão inscreve-se num projeto que poderíamos enquadrar no seio de uma perspetiva de democracia formal, ou seja, um reconhecimento pelo Estado de relações com vista a um objetivo último, a extensão da igualdade a casais homossexuais da mesma forma de contrato existente entre casais heterossexuais. Este símbolo não pretende, para o autor, elidir a necessidade de uma análise crítica da instituição, mas a opção por uma estratégia analítica de o tratar como um fim último de cidadania e não como uma maneira de regular relações enquadradas por uma determinada racionalidade legal, implica uma recusa das perspetivas analíticas queer. Como discute num texto posterior (Vale de Almeida, 2012), estas perspetivas são consideradas inadequadas para a esfera política. Ora, o meu argumento é que é esta conceção do casamento como um vazio que permite a ressignificação das normas de género e sexuais, mas que apenas é eficaz em termos de uma democracia formal, onde o reconhecimento estritamente formal dos direitos the permite manter uma ilusão de democracia mas que só se aplica para algumas posições sociais onde tal seja possivel. Numa democracia enfraquecida, de baixa intensidade como the chamou Sousa Santos (1998), marcada por um pensamento neo-liberal em termos económicos, não será esta forma de reconhecimento formal ainda um passo bastante tímido, sobretudo se acompanhado por uma discriminação formal na lei em termos da objeção à adoção? Aqui ecoa a ideia do supremo interesse da criança (Butler, 2003), sempre usada como um objeto fantasmagórico mas também um locus de ventriloquismo social, em que através desse criança que nunca pode chegar a falar, vários movimentos e pessoas conservadoras a usem para impôr a heteronormatividade como única possibilidade.

Creio que seria importante considerar e detalhar as negociações entre estas formas legais de casamento com as exclusões que o próprio privilégio do casamento implica em relação às pessoas não casadas. É evidente que, retomando a crítica de Spivak à introdução da lei contra o sati na Índia, esta lei não altera substancialmente as posições de sujeito. Esta marca estritamente formal e simbólica em relação ao casamento e o reforço simbólico que esta instituição permite manter parece antes ser uma forma de manutenção de um núcleo de valores familiares que só diferem dos tradicionais em termos do (mesmo) sexo dos nubentes. 
Em termos analíticos, e este texto visa descortinar modalidades de cidadania sexual e discuti-las analiticamente e não em termos de estratégia política ou legislativa (a mesma já existe consagrada na lei), é necessário analisaroutrosmodos deexpressãodacidadania sexual contemporânea. Ou seja, é preciso extravasar o domínio estrito do jurídico para analisar o modo como estas formas de contratualização legal são usadas na vida das pessoas. Com os dados de que dispomos, parece ser claro que a geografia do casamento entre pessoas do mesmo sexo por agora confirma que a distribuição do casamento segue uma lógica de concentração nos grandes centros urbanos, onde a homossexualidade é vista como mais aceitável e menos em desacordo com os sistemas de crenças e de representações tradicionais, mais visíveis nos meios rurais.

\section{O caso da cidadania de consumo: uma consolação para a discriminação?}

Saindo agora do frio domínio das estatísticas, para entrar nos contextos vivenciais, escolhi um caso que ilustra as múltiplas contradições da cidadania sexual que pretendo abordar neste artigo. Num estudo que realizámos em 2009, analisámos por via de uma análise temática um conjunto de entrevistas a pessoas LGBTIQ (Costa, Oliveira, \& Nogueira, 2010) e a ativistas LGBT e feministas (Oliveira, Pena, \& Nogueira, 2011). O presente texto não constitui uma apresentação do estudo de modo que me escusarei a apresentar grandes detalhes técnicos, dado que se encontra publicado. Pretendo antes focar-me numa entrevista que foi conduzida com uma das entrevistadas e que não foi analisada nesse trabalho anterior e que agora analiso recorrendo à análise de discurso. A entrevista foi semiestruturada e durou cerca de 2 horas, tendo sido realizada por uma investigadora. A entrevistada trata-se de uma mulher autoidentificada como lésbica e que reside numa pequena cidade do interior centro português. Esta jovem que designaremos como Rita (pseudónimo) tem 28 anos e é professora do ensino secundário (ginásio). Rita foi militante do Partido Comunista Português e ativista numa associação LGBTIQ, contudo hoje em dia, não participa mais nestes movimentos. A entrevista começa por narrar uma história que me parece muito habitual no contexto português fora da área metropolitana de Lisboa ou do Porto, o que é confirmado pelos estudos que desenvolvemos sobre o contexto do heterossexismo em Portugal (Costa, Oliveira, \& Nogueira, 2010):

Na rua tenho que ter muito cuidado, tenho que ter muito cuidado porque senão toda a gente sabe. E tenho receio ainda por cima porque é assim: é uma terra em que o poder está concentrado numa família e que me está a dar emprego a mim e que discriminam e se sabe provavelmente a minha situação tornar-seia muito complicada. Na escola não se sabe de nada, nada. (Rita)

A entrevistada fala da demonstração pública de afetos que nesta cidade do interior de Portugal é absolutamente interdita para ela. A sua narrativa está cheia de expressões que denotam "cuidado", "receios" e "medo". Não se trata de um medo desproporcionado, trata-se antes de uma estratégia que impede que a sua homossexualidade seja usada como critério para discriminações que, como diz, pode complicar em muito a sua situação profissional.

Este medo e a necessidade de ocultar a sua orientação sexual foi analisado no trabalho de Dana Rosenfeld (2009), que divide as homonormatividade em duas temporalidades distintas. A primeira, a que chama homonormatividade do pós-guerra e que caracteriza como sendo marcada pelas políticas de passar por heterossexual (politics of passing), ou seja, em que os indivíduos usam de um silêncio em relação à sua sexualidade ou identidade de género e tentam passar despercebidos como forma de evitar discriminações. A estratégia para ter maior aceitação passa por uma forte conformidade às normas de género e por desenvolver esforços para fazer-se passar por heterossexual, mantendo inquestionados os pressupostos heterossexuais (Rosenfeld, 2009). A outra forma de homonormatividade que a autora chama de neo-liberal é aquela que aludimos na primeira secção, ou seja, uma formação normativa que não questiona as instituições e valores heterossexuais, procurando antes a sua manutenção e inclusão dentro dessas instituições (Duggan, 2003). O excerto que apresentei, ilustra como estas temporalidades se misturam no espaço e no tempo, para produzir situações paradoxais. Assim, no mesmo país onde se aprovou uma lei do casamento e uma lei de identidade de género, mantêm-se as racionalidades da homonormatividade do pós-guerra, em que passar por heterossexual ou ser omissa ou silenciosa face à orientação sexual, garante que o sistema heteronormativo não se apropria dessa marca de estigmatização (apesar de legalmente tolerada) para a partir dela produzir discriminação. Ora, tal situação prefigura então um hiato entre a formação normativa e o sistema jurídico, bem patente neste situação, configurando a formação homonormativa como modus operandi.

Em vez de considerar esta posição como meramente contextual, a meu ver, ela configura o espaço do excepcionalismo ocidental como garante da 
igualdade e liberdade e em que gays e lésbicas são iguais perante a lei (Puar, 2007). Esta configuração de um hiato entre normas sociais e legislação especialmente fora dos meios urbanos ilustra que como este mesmo espaço, usado em comparações internacionais, como excecional em termos de direitos de pessoas LGBTIQ, está pejado de assimetrias e contradições, como parte desse mesmo espaço. Esse esforço hegemonizador face a outros países é comparado usando exclusivamente a lei como apanágio de progresso. Contudo essa opção por olhar apenas o aparelho jurídico sem ter em conta os processos de formação de sujeitos e sem mudanças mais concretas no sistema heteronormativo de género, exclui das políticas públicas outras modalidades de intervenção e isenta certas tradições e costumes de um olhar crítico. Esta opção permite fornecer mapas de direitos LGBTIQ em que a Europa sobressai como terra de oportunidades, mas esquece que os direitos não são necessariamente transpostos para a vida quotidiana, servindo em muitas situações como significados vazios e exclusivamente simbólicos.

Um outro momento da entrevista onde Rita nos dá conta desta profunda imbricação entre uma homonormatividade pós-guerra e uma homonormatividade neo-liberal é quando fala da sua relação e da necessidade que sente de vivê-la sem um olhar público, apesar da necessidade de exteriorizar esse afeto:

Sinto sempre a falta de afetos exteriores, no exterior.. isso é uma grande dificuldade para as relações homossexuais. Dai que eu também ache que as relações homossexuais não durem tanto por causa disso, porque as pessoas... é sempre no espaço interior que vivem as relações [homossexuais]. (Rita)

Referindo-se à demonstração pública de afetos, na realidade, Rita está a aludir a um espaço comum entre as duas formas de homonormatividade. No modelo pós-guerra, demonstrar os afetos em público em relação a um/a parceiro/a seria visto como destruidor da estratégia de se fazer passar por heterossexual e para isso recorriam-se a modus operandi que dificultassem a heteroidentificação com a homossexualidade. No modelo neo-liberal com o profundo chamamento para o espaço assimilacionista do privado, a mesma necessidade é deslocada para o plano da privatização da sexualidade e expressão de afetos e para o domínio do doméstico. Assim em ambas as modalidades, a heteronormatividade determina que a sexualidade e o afeto seja vivida no privado dado que o espaço público é saturado de heterossexualidade. Ora, tal raciocínio leva-nos a entender que a cidadania é sempre e desde logo sexualizada. A própria ocupação do espaço público depende da sexualidade e do género e no caso da homossexualidade ela é forcluída dessa espaço, tal como é do espaço psíquico, aquando da identificação de género inaugurada pela heterossexualização do desejo (Butler, 1997).

Mais uma vez, a mera existência de um enquadramento jurídico para admissão das relações homossexuais ao casamento não é suficiente para marcar profundamente $\mathrm{o}$ processo de constituição dos sujeitos. Até porque como mostra igualmente Butler (2003), o casamento mesmo entre pessoas do mesmo sexo continua a ser uma matriz de privilégio possível apenas para alguns tipos de relação e o Estado regula vigorosamente a relação entre casamento e o parentesco, nalguns casos, como no português, mantendo inclusivamente vedado o acesso à adoção para casais de pessoas do mesmo sexo, ainda que casados. Assim, se entende como mesmo em países onde a legislação recobre direitos LGBTIQ, esses direitos sejam diferidos ou suspensos em prol de outros interesses.

Retomemos Rita e o modo como vive então nestes espaços normativos marcados pela contradição entre o jurídico e o social. Focando-nos agora nos consumos de produtos culturais LGBTIQ:

Mas consumo livros sobre a temática, identidades, queer, e aquelas coisas todas. Consumo filmes, porque nós precisamos desse consolo ${ }^{3}$ e depois porque de um modo geral é tão complicado ser homossexual e então nós gostamos de consumir filmes muito suaves, muito agradáveis para ter um consolo [risos]. (Rita)

O tema do consolo, da necessidade de após as dificuldades inerentes a uma posição de sujeito discriminada e dominada, ao exercício de passar por heterossexual para evitar o estigma inerente a uma performance lésbica e da necessidade de privatizar os afetos encontra na formação social capitalista a possibilidade de consolação. É o próprio consumo de produtos ligados a uma identidade lésbica ou LGBTIQ comodificada, para usar um termo marxista, ou mercadorizada para usar um termo mais consentâneo com a língua portuguesa, que permite o acesso a uma cidadania sexual, vivida no privado, ligando as experiências pessoais com a possibilidade de aceder a outras experiências. Assim, repare-se na opção pelos filmes "muito suaves, muito agradáveis" que permitem à entrevistada sentir-se mais livre das contradições que diz viver. Estes permitem-lhe uma forma de escape desta vivência, descrita como privatizada, vivida no âmbito da domesticidade e fora do olhar público estigmatizador. Assim, encontra uma maneira de 
viver esta cidadania sexual fora da pólis. Deste modo, é possível analisar os contornos da cidadania sexual por via desta experiência de privatização da mesma. Num meio socialmente adverso, Rita encontra nestes produtos culturais, aquilo que lhe é vedado viver no mundo das relações sociais. Desta forma, a cidadania sexual, privatizada e domesticada, necessariamente, não reflete alterações na esfera pública, sendo que é essa mesma esfera pública hegemonicamente heterossexual que possibilita como única forma de vivência uma cidadania vivida na consolação do privado pelos agravos produzidos pela discriminação do público. Há neste discurso, um elemento muito relevante que se prende com uma necessidade de reparação por todo o efeito da estigmatização. É como se estes produtos de uma sub-cultura lésbica e gay produzissem uma ilusão de suavização dos custos pessoais da discriminação. Há aqui uma dinâmica de compensação, que poderíamos também analisar como marcas de uma cidadania sexual que só inclui aqueles/as que podem ser incluídos/as, dado que ela mesma é marcada por diferentes matrizes de opressão e privilégio. Assim, se para alguns/algumas é possível aceder ao quadro de direitos definidos na legislação portuguesa, como o direito de casar, direito a ser protegido da discriminação e direito a união de facto, para outros/as esses direitos não se colocam a não ser numa esfera de um imaginário, vivido no privado.

Rita, na sua entrevista, diz-nos:

$\mathrm{Eu}$ acho assim, quando algumas situações economicamente estão resolvidas as pessoas podem se dar ao luxo de se centrar noutras questões. Eu falo no теи caso em especifico. Se eu tivesse uma situação económica que me permitisse estar livre e despreocupada eu seria absolutamente assumida. (Rita)

Ou seja, é a posse de capital que permite o usufruto pleno dos direitos de acordo com esta entrevista. É através do acesso a este capital que a cidadania sexual pode ser vivida dentro do quadro da formação social capitalista de matriz neo-liberal, onde através do poder aquisitivo se pode aceder a essa assunção identitária, a esse momento libertador e simultaneamente "livre". Assim assumir-se, é na gramática política desta entrevistada, um "luxo" e como tal, só alguns/algumas podem verdadeiramente aceder-lhe. Esta dependência de uma situação económica é muito relevante neste contexto. No jogo do exercício do acesso ás identidades reclamadas publicamente, só alguns encontram a situação de lhe poderem aceder. Por mais plasmadas que estejam nas leis, há a necessidade de um contexto social favorável ou em alternativa, de uma situação económica que possibilite aceder a estas identidades sem se correr o risco de se tornarem perigosas em termos de ajustamento social ou seja de se tornarem passíveis de discriminações. Assim é necessário ter em conta que tanto a estratégia de adaptação a um contexto heteronormativo bem como a expressão da homonormatividade são duas faces da mesma moeda em sociedades contemporâneas onde a legislação já permite o acesso a direitos no plano formal, mas que no plano das práticas sociais ainda existem discriminações baseadas na sexualidade. Desta forma, tanto a homonormatividade como a adaptação a um contexto discriminatório são duas expressões de uma mesma economia política, a heteronormativa. $\mathrm{Na}$ leitura que proponho, considero que ambas as modalidades estão presentes, tanto na adaptação (por silenciamento) como na adopção de estratégias de uma cidadania sexual de consolação, como é ditado pela homonormatividade.

Um caso semelhante é encontrado na análise de Machado \& Prado (2005) sobre movimentos sociais LGBTIQ na cidade de Belo Horizonte, onde a comercialização de uma indústria destinada a consumidores LGBTIQ cria uma diferenciação interna dentro do grupo, nomeadamente por questões ligadas à posse de riqueza. Assim, seguindo a lógica neoliberal cria-se ainda uma outra diferenciação de classe que põe em causa o próprio poder emancipatório do movimento social, adequando-o ao projeto neo-liberal e transformando-o em mais um produto do capitalismo. As próprias identidades gay e lésbicas são assim alvo deste processo de comodificação. Esta análise ilustra o modo como formação social capitalista neo-liberal e normas de género se cruzam para produzir estas "necessidades" identitárias, que acabam por servir estes dois amos: normalização (e consequente assimilação) e comodificação. Estas pressões criam pois uma dupla hierarquia dentro do grupo em análise, separando e transformando em alteridades, os indivíduos não conformes ao género e seus ditames normativos dentro do quadro da heterossexualidade hegemónica e por outro lado, segmentando o grupo em termos de poder aquisitivo e necessariamente em termos de classe social. Assim, os outros desta comunidade fraturada são os que têm menos poder aquisitivo, não podendo aceder às consolações proporcionadas pelo comércio rosa e aqueles que são lidos como abjetos e que põe em causa as "conquistas" de cidadania sexual, forçosamente homonormativas e marcadas pela assimilação. Assim a cidadania sexual tem um outro caráter também homonormativo e classista, tornando-a possível apenas a alguns dentro do grupo LGBTIQ. 


\section{Cidadania Sexual, paradoxal e exclusiva ou conclusão guiada por Rita}

A cidadania sexual não é uma panaceia universal. Raramente algum conceito ou construto o é. Acidadania sexual necessita de ser pensada à luz dos quadros de referência psicossociológicos e históricos de onde foi gerada. Recorrendo a Derrida (1981), invoco para concluir, o termo pharmakon. O pharmakon é um termo grego que significa simultaneamente "cura" e "veneno" usado por Platão e que Derrida utiliza como forma de recusar as lógicas binárias e de analisar a indecibilidade que o conceito comporta. Tal é o caso da cidadania sexual. Trata-se não somente de uma possibilidade de habitar a esfera pública a partir da sexualidade nem de um conceito que apenas traduz a normalização e a assimilação necessárias para habitar essa mesmo esfera pública hegemonicamente heterossexualizada. Ou seja, trata-se também ela de um conceito polissémico e que concorre a múltiplas possibilidades analíticas.

O mesmo processo é ilustrado pela questão das conquistas jurídicas, ou seja das alterações na legislação que permitem o acesso de casais do mesmo sexo ao casamento. Não se trata neste artigo de criticar essa possibilidade, trata-se antes de a problematizar e analisar a questão tendo em conta os seus efeitos em contextos sociais dispares. Assim, também não se considera aqui exclusivamente uma visão nem pró-casamento nem anticasamento recorrendo aos habituais argumentos. Trata-se antes de considerar um espetro mais amplo de possibilidades de efeitos desta legislação na vida dos indivíduos.

Assim enfatizei neste trabalho, esse caráter pharmakon destes processos sociais, analisando-os com uma atenção aos efeitos de uma formação social capitalista de matriz neoliberal como pano de fundo para processos sociais marcados pela normalização da população LGBTIQ que consequemente traça linhas de hierarquização dentro dos grupos, aproximando uns/ umas do modelo do bom cidadão e excluindo outrxs ${ }^{4}$ para uma zona de abjeção, marcada pela ausência de inteligibilidade como sujeitos e como humanos. Este processo pode ser extensível a todos os outros abjetos (Butler, 1993), com particular ênfase naqueles que estão para lá do inteligível pelas normas de género. Como mostra o trabalho de Silva, Toneli \& Becker (2010), numa análise e aplicação da noção de abjeto ao corpo travesti, estes corpos são entendidos como estando fora da inteligibilidade social, portanto de tal modo fora da (hetero)norma que deixam de gozar do estatuto de sujeito e as suas vidas são ilegitimadas por essa abjeção. Juracy Toneli (2008) apresenta também uma discussão do modo como estas normas de género são inclusivamente uma pauta para a definição de critérios médicos e psiquiátricos em termos de saúde, nomeadamente pela sua integração nos manuais de referência para o diagnóstico de perturbação mental, como é o caso do DSM. Estes (não) sujeitos são pois negados e não apenas excluídos na base de um critério heteronormativo que marca os limites da inteligibilidade do humano. Uma análise feminista queer implica pois uma particular atenção a esta normatividade do género dentro do quadro de uma heterossexualidade hegemónica (Butler, 1993).

É necessário todavia considerar que estes projetos como seja o casamento têm uma eficácia performativa no plano político. Permitem manter assuntos ligados aos direitos sexuais na agenda política e permitem que alguns indivíduos concretizem determinados projetos de vida, relacionais e afetivos. Mas recordemos Derrida e o seu uso do pharmakon, não perdendo de vista as subalternas analisadas por Gayatri Spivak. Este trabalho também permite mostrar que uma mudança legal não produz forçosamente mudanças nas posições de sujeitos, ou seja sem mudança nas posições de sujeitos, os efeitos das leis são sempre mitigados pelas normas pré-existentes e não permitem toda a extensão da mudança necessária para alterar de fato estas situações.

A ilustração empírica que usei da entrevista realizada a Rita serviu de guia a esta análise, pois ela ilustra as contradições que encontramos no mesmo país que aprovou o casamento entre pessoas do mesmo sexo e que apesar dessa aprovação, tomando em conta as suas condições de existência, não lhe é possível sequer sair do quadro de uma homonormatividade típica do pós-guerra. Como mostra Fernando Cascais (2006), quando aponta algumas das características dos grupos LGBT em Portugal, parte deste grupo ainda se encontra marcado simultaneamente pela menorização, invisibilidade, objectificação e acomodação. $\mathrm{O}$ que pretendo mostrar neste texto é a segmentação dentro deste grupo aparentemente todo tomado como igual. Para tal concorrem as coordenadas que enunciei na primeira seção, para além do próprio contexto que Cascais (2006) analisa, a homonormatividade como decorrência das normas de género dentro do quadro da heterossexualidade hegemónica e sistema capitalista de matriz neo-liberal com repercussões na segmentação desta comunidade. Como ilustração do caso, recorri tanto às estatísticas e discursos sobre o casamento bem como aos discursos de uma lésbica de classe média, mostrando que dentro do mesmo país, com uma legislação igualitária, há quem aceda a esses direitos e outrxs, para quem tais privilégios (e já não 
direitos) são inatingíveis. Por outro lado, este trabalho permite evidenciar o modo como a adaptação a um contexto marcado pela discriminação em função das sexualidades e do género, bem como as estratégias homonormativas de consolação desse esforço, são duas faces da mesma economia política heteronormativa.

\section{Notas}

1 Dados solicitados, por mim, ao Ministério da Justiça sobre casamentos entre pessoas do mesmo sexo em 2010.

2 Já que bissexuais, trans, intersexos e queer raramente são equacionados nesta questão, tornando a coligação LGBTIQ uma mera esperança em vez de uma realidade.

3 Consolo é aqui usado no sentido de consolação ou reparação.

4 Esta marca do $\mathrm{x}$ pretende traduzir a indecibilidade do género dado que estes indíviduos são aqueles disconformes às normas de género.

\section{Agradecimentos}

Este artigo foi financiado pela bolsa de pósdoutoramento atribuída pela Fundação para a Ciência e Tecnologia (ref: SFRH / BPD / 62852 / 2009) ao autor.

\section{Referências}

Abu-Lughod, L. (2002). Do Muslim women really need saving? Anthropological reflections on cultural relativism and its others. American Anthropologist, 104, 783-790.

Butler, J. (1990). Gender trouble: Feminism and the subversion of identity. New York: Routledge.

Butler, J. (1993). Bodies that matter: On the discursive limits of "sex". New York: Routledge.

Butler, J. (1997). The psychic life of power: Theories in subjection. Stanford, CA: Stanford University Press.

Butler, J. (2003). O parentesco é sempre tido como heterossexual? Cadernos Pagu, 21, 219-260.

Butler, J. (2004). Undoing Gender. New York: Routledge.

Carneiro, N. S. (2009). Homossexualidades: uma psicologia entre ser, pertencer e participar. Porto: Livpsic.

Cascais, A. F. (2006). Diferentes como só nós. O activismo português em três andamentos. Revista Crítica de Ciências Sociais, 76, 109-126.

Cooper, D. (2006). Ative citizenship and the governmentality of local lesbian and gay politics. Political Geography, 25, 921-943.

Costa, C. G., Oliveira, J. M., \& Nogueira, C. (2010). Os discursos das pessoas LGBT. In C. Nogueira \& J. M. Oliveira (Eds.), Estudo sobre a discriminação em função da orientação sexual e da identidade de género (pp. 211-242). Lisboa: Comissão para a Cidadania e Igualdade de Género.

Derrida, J. (1981). Dissemination. London: Continuum.

Duggan, L. (2003). The twilight of equality: Neoliberalism, cultural politics and the attack on democracy. New York: Beacon Press.

Evans, D. T. (1993). Sexual citizenship: The material construction of sexualities. London: Routledge.
Foucault, M. (1976). Histoire de la sexualité. Paris: Gallimard.

Halberstam, J. (2005). In a queer time and place: Transgender bodies, subcultural lives. New York: New York University Press.

Halberstam, J. (2011). The queer art of failure. London: Duke University Press.

Hall, S. (2011). The neo-liberal revolution. Soundings, 48, 9-27.

Jagose, A. (2009). Feminism's queer theory. Feminism and Psychology, 19, 157-174.

Machado, F. V. \& Prado, M. A. (2005). Movimentos homossexuais: a constituição da identidade coletiva entre a economia e a cultura. O caso de dois grupos brasileiros. Interações, 19, 37-50.

Marinucci, M. (2010). Feminism is queer: The intimate connection between queer and feminist theory. London: Zed Books.

Marshall, T. H. (1950). Citizenship and social class. Cambridge: Cambridge University Press.

Morin, S. (1977). Heterosexual bias in psychological research on lesbianism and male homosexuality. American Psychologist, 32, 629-637.

Nogueira, C. \& Oliveira, J. M. (2010). Estudo sobre a discriminação em função da orientação sexual e da identidade de género. Lisboa: Comissão para a Cidadania e Igualdade de Género.

Nogueira, C. \& Silva, I. (2003). Cidadania: construção de novas práticas em contexto educativo. Porto: Asa.

Oliveira, J. M., Pena, C., \& Nogueira, C. (2011). Lesbian Feminism or Lesbian Feminists? - Portuguese Lesbians Speak Out. Feminism \& Psychology, 21, 228-232.

Puar, J. (2007). Terrorist Assemblages: Homonationalism in queer times. London: Duke University Press

Richardson, D. (2004). Locating sexualities: From here to normality. Sexualities, 7, 391-411.

Richardson, D. (2005). Desiring Sameness? The Rise of a Neoliberal Politics of Normalisation. Antipode, 37, 515-535

Rosenfeld, D. (2009). Heteronormativity and homonormativity as practical and moral resources: The case of lesbian and gay elders. Gender \& Society, 23, 617-638.

Santos, A. C. (2009). Molduras públicas de performatividade queer e representação mediática em Portugal. Ex Aequo, 20, 97-112.

Silva, F., Toneli, M. J., \& Becker, S. (2010). Ele é feita para apanhar/ Ela é bom de cuspir/maldito Geni: especulações sobre a condição de abjetos vivida por travestis. Revista Científica Eletrónica de Psicología, 10, 250-262.

Sousa Santos, B. (1998). Reiventar a democracia. Lisboa: Gradiva.

Sousa Santos, B. (2005). A crítica da governação neoliberal: O Fórum Social Mundial como política e legalidade cosmopolita subalterna. Revista Crítica de Ciências Sociais, 72, 7-44.

Spivak, G. (1993). Can the Subaltern Speak? In P. Williams \& L. Chrisman (Orgs.), Colonial discourse and post-colonial theory: a reader (p. 66-111). Hertfordshire: Harvester Wheatsheaf.

Toneli, M. J. (2008). Diversidade sexual humana: notas para a discussão no âmbito da psicologia e dos direitos humanos. Psicologia Clínica, 20, 61-73.

Trans World Order. (2012). Occupride. Acesso em 11 de março, 2013, em http://occupywallst.org/article/pride-seasonoccupy-wall-street-calls-trans-and-qu/ 
Oliveira, J. M. Cidadania sexual sob suspeita: uma meditação sobre as fundações homonormativas e neo-liberais

Vale de Almeida, M. (2009). A chave do armário: homossexualidade, casamento e família. Lisboa: Imprensa de Ciências Sociais.

Vale de Almeida, M. (2012). Tripping over history: Same sex marriage in Portugal. Anthropology Today, 28, 24-26.

Wittig, M. (2005). El Pensamiento heterosexual y otros ensayos. Madrid: Egales.

Recebido em: 28/06/2012

Revisão em; 28/08/2012

Aceite em: 11/09/2012
João Manuel de Oliveira é Investigador em Estudos de Género e Teoria Feminista no Centro de Psicologia da Universidade do Porto. Endereço: Faculdade de Psicologia e Ciências da Educação da Universidade do Porto. Rua Alfredo Allen. Porto, Portugal. CEP 4200-135. Email: joao.m.oliveira@gmail.com

\section{Como citar:}

Oliveira, J. M. (2013). Cidadania sexual sob suspeita: uma meditação sobre as fundações homonormativas e neoliberais de uma cidadania de "consolação". Psicologia \& Sociedade, 25(1), 68-78. 